\title{
Study on Saravan Fault Activities on the Basis of Earthquake and Morphotectonics Evidences
}

\author{
Shahram Habibi Mood*, Mohsen Jami, Javad Shahraki, Nazanin Sarhaddi \\ Department of Geology, College of Basic Science, Zahedan Branch, Islamic Azad University, Zahedan, Iran \\ Email: "Shahramhabibimood@gmail.com, Mohsenjami84@yahoo.com
}

Received 5 December 2015; accepted 12 February 2016; published 16 February 2016

Copyright (C) 2016 by authors and Scientific Research Publishing Inc.

This work is licensed under the Creative Commons Attribution International License (CC BY).

http://creativecommons.org/licenses/by/4.0/

(c) (i) 0 pen Access

\begin{abstract}
Saravan Fault is the biggest fault in southeast of Iran. It is Right-Slip fault. It has been extended from northwest to southeast. It is important to evaluate tectonic activities along this fault because it is adjacent to the city and various villages. It's found that there are various tectonic activities along this fault. In this paper, it has been studied on affecting this fault on geomorphology of the zone. Average values of some indices such as Mountain Font Sinuosity and V ratio have been studied that they are 1.76 and 0.77 , respectively. It suggests that there are serious tectonic activities in the zone. There are some evidences such as Right-Slip fault along artificial river channel that indicates its youngest stage means Late Cenozoic. According to studies, Saravan Fault is more active in the middle zone than northwest and southeast ends.
\end{abstract}

\section{Keywords}

Saravan Fault, Earthquake, Morphotectonic, Geomorphologic, Dextral Strike-Slip

\section{Introduction}

The Saravan fault is located in southeastern of Iran, $27^{\circ}$ to $28^{\circ}$ latitudinally and $61^{\circ} 30^{\prime}$ to $62^{\circ} 45^{\prime}$ longitudinally, that has been covered by Geological Map 1:250000 of Saravan. In Iran Geotectonic Division, Saravan fault and range of its performance are located in the suture zone and the east Flysch of Iran [1]. The most stones of this region are Flysch of Eocene. This fault where extended from southern range of eastern-northeastern Saravan Mountains and it is $270 \mathrm{~km}$ in length and it has been separated Ba Damo-Siyahan Stratigraphy from Saravan [2].

The most part of the fault (all over Saravan plain) has been extended N50W generally and about $50 \mathrm{~km}$ of the

"Corresponding author.

How to cite this paper: Mood, S.H., Jami, M., Shahraki, J. and Sarhaddi, N. (2016) Study on Saravan Fault Activities on the Basis of Earthquake and Morphotectonics Evidences. Open Journal of Geology, 6, 79-86.

http://dx.doi.org/10.4236/ojg.2016.62008 
east fault (Dehak village to the border between Pakistan) is also roughly along east-west [3]. It is found that the main process of these structures such as the main faults and the axis of folds and so on have been extended from northwestern to southeastern, i.e. N130 - 140.

Morphotectonic Analysis Method that used to interpret Geological Structures has been derived from Topographic and telemetric data. This analysis examines the spatial relationships between geomorphic (Landforms) and tectonic processes that caused them to be explored and understood by morphotectonic in line with the dynamic or kinetic analysis of the process.

\section{The Study of Geomorphologic Indices}

Some quantitative indices has been considered to evaluate the ratio of regional geotectonic activities, these indices indicate movement and the lifting-up one block than other block along the fault and the morphotectonic indications resulted from reversed and extensive movements.

In this study, it has been considered not only the new Neotectonic evidences but also parameters such as mountain front sinuosity, rate index (V), Hydraulic Gradient Index of Stream (SL) that has carried out by field sampling, using satellite images, topographic maps and SRTM data.

\section{The Mountain Front Sinuosity}

In fact, this index indicates the relationship between tendency of rivers to produce irregular front and vertical tectonic activity to produce a straight front on the mountain that surface processes lead to be irregularity of mountain front and morphotectonic processes lead to be these fronts smoother and linear. On the basis of resulted calculation, the range of changes is a value higher than 1 in Smf index [4].

If the ratio of this index is equal to 1 , it indicates the activity of geotectonic processes and the youth of mountains, and the increase of this value indicates lesser tectonic activities and the dominance of surface processes. In following relation, Lmf value is the length of the mountain meander and Ls is the length of the straight line of the mountain front.

According to the above mentioned features, the mountain front along Saravan fault is divided into 20 fronts to obtain Smf index (Figure 1 \& Figure 2) and then it was calculated from the north to the south for different blocks.

By studying these mountain fronts parallel to the fault, it can be determined relative intensity of tectonic activities and also the regions where have the highest lifting-up activities. Then, by comparing it with the other morphometric indices, it can be obtained the final sum up of the condition of activities and active regions along the Saravan fault (Table 1).

As it is shown in Table 1, the calculated values of Smf index are small (lower than 2) for the most regions and it indicates that there is a relatively high activity in all over Saravan fault. In some regions, the considered mountain fronts have the least curve and sinuosity then their Smf index is the least.

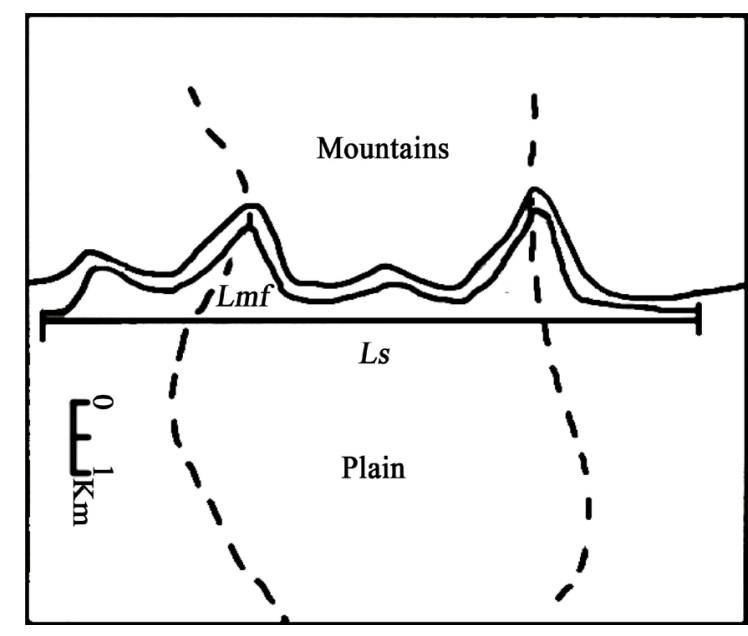

Figure 1. Method of calculating Smf index. 


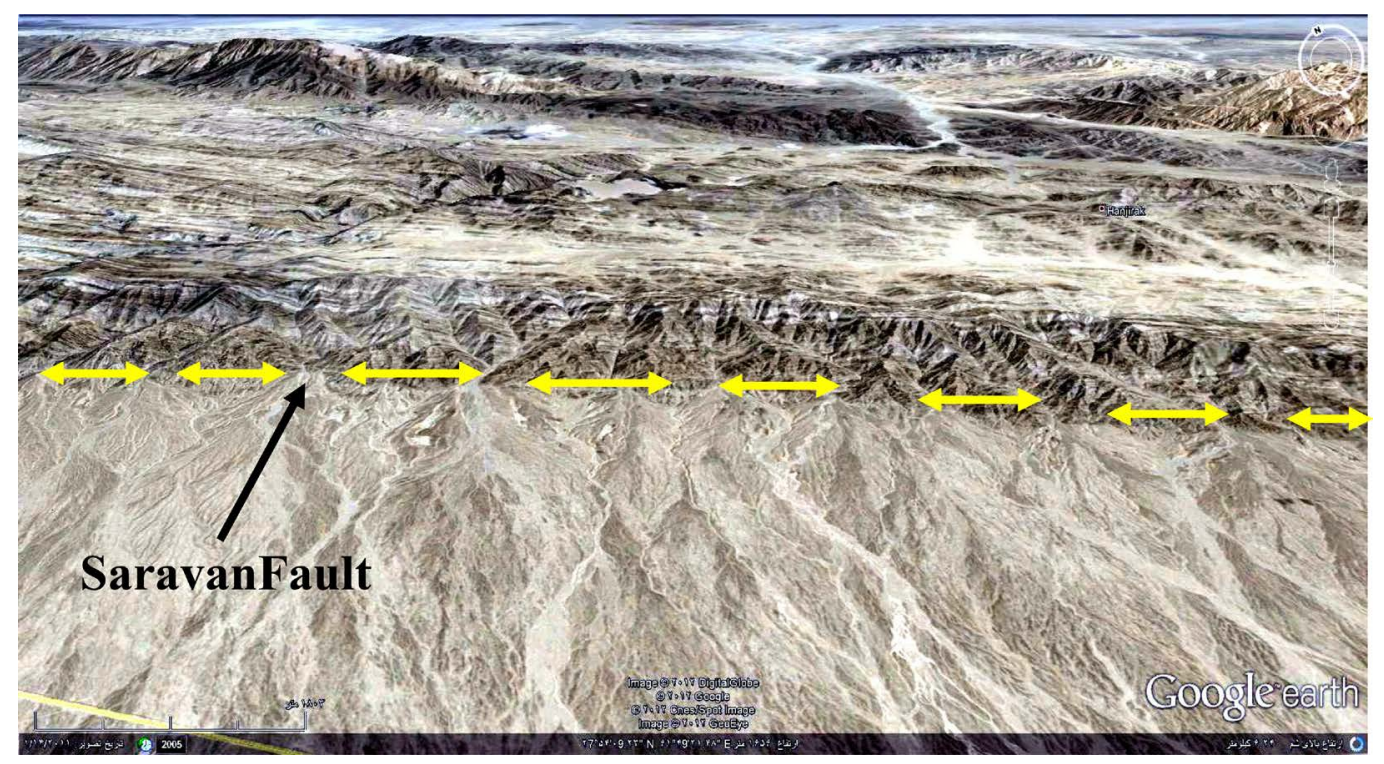

Figure 2. Calculation of Smf index, measurement direction is from north to south.

Table 1. The derived numbers for Smf index in 24 blocks of Saravan fault.

\begin{tabular}{cccccccc}
\hline Front & Ls & Lmf & Smf & Front & Ls & Lmf & Smf \\
\hline 1 & 3.4 & 5.4 & $\mathbf{1 . 6}$ & 11 & 7.4 & 12 & $\mathbf{1 . 6}$ \\
2 & 5.6 & 8.7 & $\mathbf{1 . 5}$ & 12 & 6.5 & 10.6 & $\mathbf{1 . 6}$ \\
3 & 6.5 & 9.1 & $\mathbf{1 . 4}$ & 13 & 5.7 & 8.7 & $\mathbf{1 . 5}$ \\
4 & 5.3 & 9.5 & $\mathbf{1 . 8}$ & 14 & 6.06 & 8.3 & $\mathbf{1 . 4}$ \\
5 & 5.1 & 8.2 & $\mathbf{1 . 6}$ & 15 & 5.9 & 9.4 & $\mathbf{1 . 6}$ \\
6 & 5.9 & 7.7 & $\mathbf{1 . 3}$ & 16 & 4.5 & 6.4 & $\mathbf{1 . 4}$ \\
7 & 5.5 & 6.8 & $\mathbf{1 . 2}$ & 17 & 4.9 & 5.8 & $\mathbf{1 . 2}$ \\
8 & 5.6 & 8.5 & $\mathbf{1 . 5}$ & 18 & 5.2 & 8.5 & $\mathbf{1 . 6}$ \\
9 & 3.7 & 7.5 & $\mathbf{2}$ & 19 & 4.1 & 6.8 & $\mathbf{1 . 6}$ \\
10 & 5.9 & 8.5 & $\mathbf{1 . 4}$ & 20 & 4.4 & 7.3 & $\mathbf{1 . 7}$ \\
\hline
\end{tabular}

Since it can't be expressed any idea about regional tectonic based upon one morphotectonic index, thus other indices were also studied and finally the regional tectonic activities are determined according to all indices.

\section{Truncated Percentage Index (Cleaved) of Mountain Front (Facet \%)}

Facet is defined as triangular or polygonal morphology which is created between the interfaces of two channels resulting from erosion (Figure 3). The percentage of Facet in mountain front or F\% is another quantitative index to determine relative geotectonic activity of a mountain front which consists of the ratio of the total length of facets in a mountain front (Lmfd) to the length of straight line against it (Ls). A mountain front is considered truncated if it includes several definite and significant channels, and divided it into distinct facets and clearly causes to deviat the contour lines in the topographic maps. Some of the facets might have been eroded by channels which cause to be irregularity of its morphology that it is found in the maps and images. More active Mountain fronts have less truncation and appear as a continuous mountainous front with great and definite facets that have little internal truncation.

The percentage of truncation or F\% has been approximated 100\% in the active mountain fronts which it also reduces by decreasing the activity. This index is ranged $0 \%-100 \%$ (Table 2). The mountain along Saravan fault was divided into 28 blocks to obtain faceting index (F\%) and then this index was calculated for different blocks from north to south. 


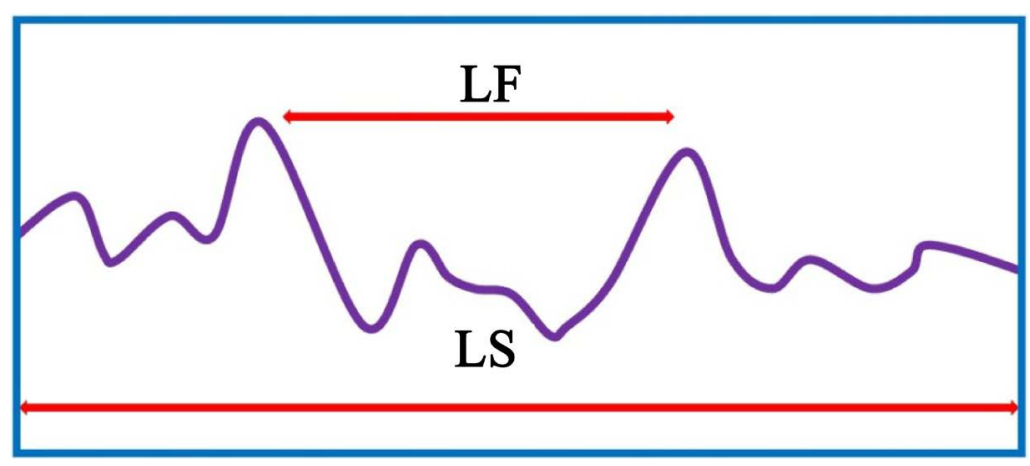

Figure 3. Method of calculating facet index [5].

Table 2. The obtained numbers for index F\% in 28 blocks of Saravan fault.

\begin{tabular}{cccc}
\hline Front & Ls & Lmfd & F\% \\
\hline $\mathbf{1}$ & 7447 & 5950 & 79.8 \\
$\mathbf{2}$ & 7343 & 4820 & 65.6 \\
$\mathbf{3}$ & 6850 & 5370 & 78.3 \\
$\mathbf{4}$ & 5249 & 4550 & 86.6 \\
$\mathbf{5}$ & 4950 & 3959 & 79.9 \\
$\mathbf{6}$ & 4241 & 3557 & 83.8 \\
$\mathbf{7}$ & 3533 & 2780 & 78.6 \\
$\mathbf{8}$ & 5824 & 4057 & 69.6 \\
$\mathbf{9}$ & 5615 & 3108 & 55.3 \\
$\mathbf{1 0}$ & 6407 & 4640 & 72.4 \\
$\mathbf{1 1}$ & 6908 & 4541 & 65.7 \\
$\mathbf{1 2}$ & 5784 & 4046 & 69.9 \\
$\mathbf{1 3}$ & 7290 & 4670 & 64.06 \\
$\mathbf{1 4}$ & 5460 & 3494 & 63.9 \\
\hline
\end{tabular}

Most active regions based on these calculations are located on the middle part of Saravan Fault. It means that the least faceting of mountain front has been created by current streams in the region. But the southern and northern regions of Saravan Fault have lesser values of F\% and according to this index; the level of relative lifting-up activity is less. These results are similar to the results of mountain front sinuosity significantly.

\section{Length-Gradient Stream Index (SL)}

Stream gradient index is one of the indices to evaluate active tectonic in relation to the shape of stream channels that defined with the following equation: [6]

$$
S L=(\Delta H / \Delta L \times L)
$$

where $\Delta H / \Delta L$ is local stream gradient ( $\Delta H$ is height differential of the range and $\Delta L$ is the range length) and ( $L$ ) is channel length from the straight stream line to the center that its gradient is calculated or in other words, $(L)$ is the total channel length from the point which index is calculated (Figure 4) to the highest channel point [6]. SL index in different parts of fault has been studied for 10 basins. The given index shows different SL values in different parts of the fault which are given in the rows 1 - 10 of Table 3 . The obtained results represent that the fault is active.

Table 3 shows the obtained values of SL for the important streams that passes through Saravan fault, therefore are affected by its tectonic movements. As a whole, SL values have a different shifting range on the basis of structural geotectonic activity and its position in a structural state, topographic status, rate of flow and the lithologic type. 


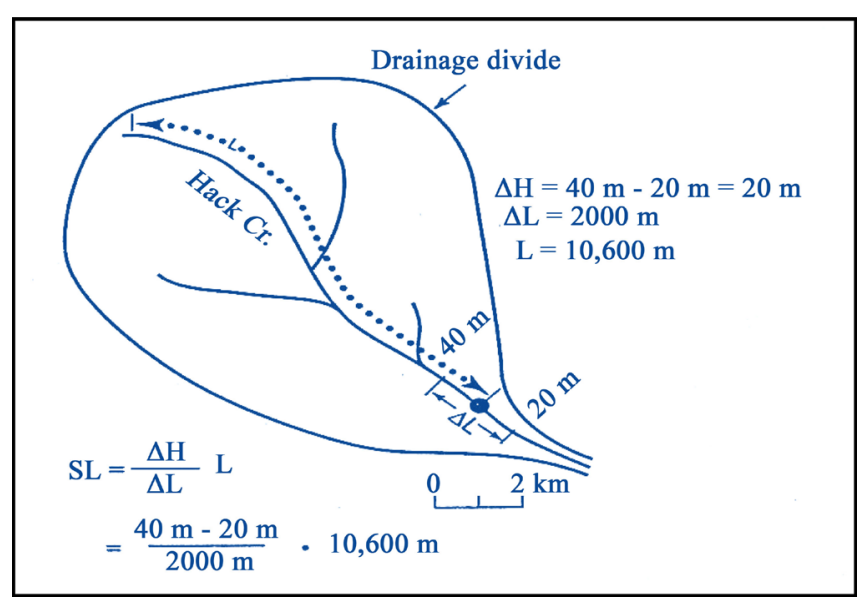

Figure 4. Method of calculating SL index.

Table 3. The obtained numbers for SL index.

\begin{tabular}{cccc} 
Number & SL & Number & SL \\
\hline 1 & $\mathbf{1 0 6}$ & 6 & $\mathbf{1 5 8}$ \\
2 & $\mathbf{2 1 6}$ & 7 & $\mathbf{9 8}$ \\
3 & $\mathbf{3 6}$ & 8 & $\mathbf{1 6 5}$ \\
4 & $\mathbf{2 8 6}$ & 9 & $\mathbf{3 4 0}$ \\
5 & $\mathbf{3 1 2}$ & 10 & $\mathbf{2 3 6}$ \\
\hline
\end{tabular}

As it can be shown in the above table, SL values have significant numerical differences as compared with each other. Because the value of SL difference can be unexpected in different streams regarding some parameters such as stream length. It can be also observed that streams 4 and 9 where located in the middle part of Saravan fault have high SL index.

Therefore, it can be said that geotectonic movements, especially lifting-up movements have increased the stream gradient. As well, an important factor such as lithologic matter can be also influenced on the SL value. Hence, more resistant lithology, more SL value and less resistant lithology, less SL value.

\section{Ratio index $\mathrm{V}$}

$\mathrm{V}$ ratio index represents a relation between the width of valley bottom near to the mountain front and the mean height of its top chords that can be calculated the ratio of tectonic activities and regional erosion relatively and $\mathrm{V}$ ratio can be obtained by using this method (Figure 5) as following: [6] [7]

Equation 1-1

$$
V=A V / A C
$$

This ratio gives us information about regional lifting-up so that if its value is about 1 , the valley is $U$ shape or if the value is very small, the valley is $\mathrm{V}$ shape that can indicate the vertical performance of active tectonics. The values more than 1 represent that the width of the valley is higher than its depth and regional tectonic activities has been approximately stopped.

The measured values of $\mathrm{V}$ index are shown for the case study of region in (Table 4).

According to the above table, the least value of $\mathrm{V}$ ratio is related to Saravan regions and zarawy and sheikh Rostam villages. In the regions with high $\mathrm{V}$ ratio, Meander streams are flowing and in the regions with low $\mathrm{V}$ ratio, the streams are flowing in strength with less width.

\section{Study on Tectonic Earthquake}

\subsection{Historical Earthquakes}

As history of past earthquakes with available experimental instructions can be used to access knowledge of his- 


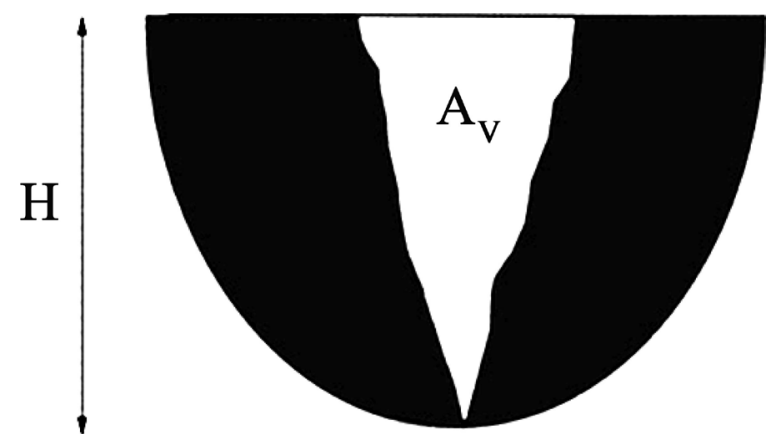

Figure 5. Indicates the method of calculating parameter of $\mathrm{V}$ ratio.

Table 4. The values of V index along Sravan fault.

\begin{tabular}{cccc}
\hline Zone & Av $\left.\mathbf{( m}^{\mathbf{2}}\right)$ & AC $\left.\mathbf{( ~ m}^{\mathbf{2}}\right)$ & $\mathbf{V r}$ \\
\hline $\mathbf{1}$ & 43,730 & 55,970 & 0.78 \\
$\mathbf{2}$ & 34,890 & 44,980 & 0.77 \\
$\mathbf{3}$ & 32,679 & 49,700 & 0.65 \\
$\mathbf{4}$ & 39,740 & 56,330 & 0.7 \\
$\mathbf{5}$ & 31,370 & 48,990 & 0.64 \\
$\mathbf{6}$ & 40,780 & 52,690 & 0.77 \\
$\mathbf{7}$ & 52,720 & 51,900 & 1.01 \\
$\mathbf{8}$ & 33,240 & 43,220 & 0.76 \\
$\mathbf{9}$ & 33,480 & 33,260 & 1 \\
$\mathbf{1 0}$ & 37,800 & 50,230 & 0.75 \\
$\mathbf{1 1}$ & 35,760 & 44,780 & 0.79 \\
$\mathbf{1 2}$ & 53,990 & 54,680 & 0.98 \\
$\mathbf{1 3}$ & 54,789 & 55,670 & 0.98 \\
\hline
\end{tabular}

torical earthquakes, it is clear that there are many problems in this field. The former historians have explained some earthquakes similarly then it causes to estimate the past earthquakes imprecisely. Studying on history of the past earthquakes (ancient, historical and 20th century) in an area is one of the important and basic data to estimate and to know historical data from descriptions of earthquake events. It is clear that the history of earthquakes in long intervals should be gathered and studied to access the specifications of tectonic earthquake. Historical earthquakes can be known on the basis of historical books but there isn't any precise data about the exact focus of earthquakes because there weren't any modern instruments and tools at the last time. Some historical earthquakes have been recorded in the studied area as following:

\section{Earthquake}

In this year, a strong earthquake occurred in Sistan that many houses were demolished. Hirmand River was dried twenty years after this earthquake and famine and pestilence were other dangerous problems in this time [8]. Also, Barbarians record in the first "Iran Earthquakes Catalogues" that Sistan was shaken with an earthquake in magnitude of 7 and 7.5 Richter for two times in 815.

\section{Earthquake}

In Qajar period (1838), a horrible earthquake also occurred in Sistan (along eastern boundaries of Loot Plain). It destroyed the deserts and covered about $150 \mathrm{~km}$. on the westside, the lowlands were destroyed as caravan ways weren't secure and safe till many years later. All villages at a distance of $75 \mathrm{~km}$ from this earthquake were destroyed but some people were killed and its aftershocks have been lasted for two years [8].

\subsection{Instrumental Earthquake}

It is necessary to study on recorded instrumental earthquakes that occurred between 1900 and 2009 to determine 
earthquake formula of the studied area. We have taken the earthquakes in magnitude of more than 3 in local scale. It covers an area, $150 \mathrm{~km}$, with a capital named Saravan with geographical coordinates (Longitude: 62 ${ }^{\circ} 33^{\prime}$ and Latitude: $27^{\circ} 36^{\prime}$ ). This information has been gathered with international catalogues (ISC, ISS, and USGS), earthquake databank and International Institute of Earthquake Engineering. Instrumental Earthquake Databank of this area has been presented in attachment 1 (Figure 6).

\section{Maximum Calculation of Peak Ground Acceleration (PGA)}

Peak Ground Acceleration (PGA) can be calculated by Formula 5 and its result has been presented in Table 5.

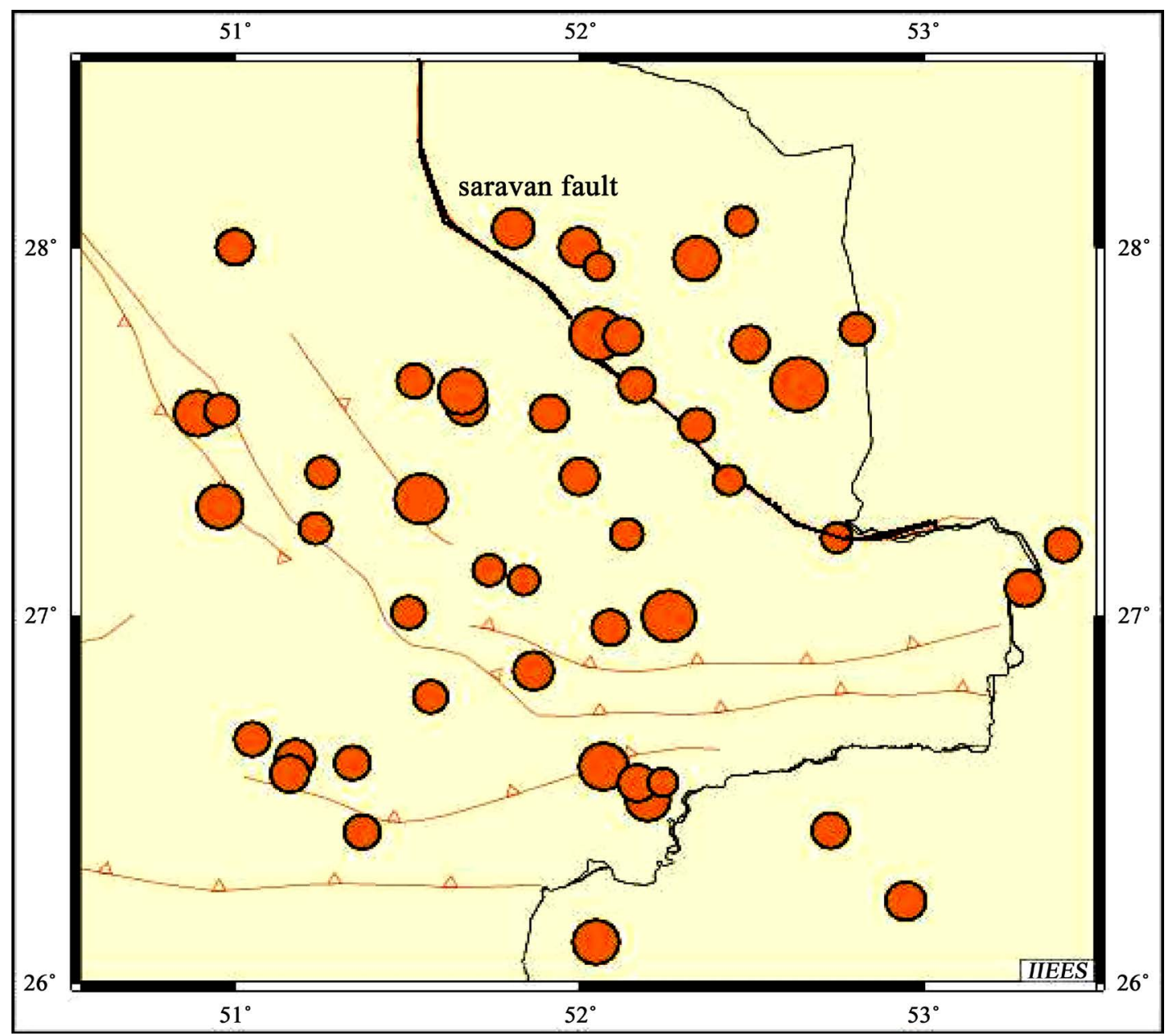

Figure 6. Focal location of instrumental earthquakes in Saravan between 1900 and 2014.

Table 5. Estimation of maximum calculation of peak ground acceleration on Saravan from surrounding fault.

\begin{tabular}{cccccccccc}
\hline Fault Name & R(KM) & MS & & & PGA & & Av \\
\hline F1 & 44 & 8 & 0.12 & 0.21 & 0.19 & 0.42 & 0.34 & 0.29 \\
F2 & 69 & 7.5 & 0.11 & 0.13 & 0.14 & 0.2 & 0.11 & 0.13 \\
F3 & 29 & 7.8 & 0.29 & 0.26 & 0.25 & 0.57 & 0.47 & 0.36 \\
F4 & 54 & 7.4 & 0.13 & 0.13 & 0.15 & 0.24 & 0.16 & 0.16 \\
F5 & 69 & 7.2 & 0.15 & 0.12 & 0.12 & 0.1 & 0.1 & 0.11 \\
F6 & 64 & 7.5 & 0.12 & 0.12 & 0.15 & 0.23 & 0.13 & 0.15 \\
F7 & 85 & 7.9 & 0.14 & 0.11 & 0.13 & 0.2 & 0.11 & 0.13 \\
\hline
\end{tabular}




\begin{tabular}{cccccccccc} 
Continued & \multicolumn{10}{c}{} \\
\hline Zaboli Fault & 54 & 8.07 & 0.2 & 0.18 & 0.17 & 0.39 & 0.28 & 0.23 \\
Saravan Fault & 13 & 8.09 & 0.56 & 0.55 & 0.6 & 0.53 & 1.3 & 0.7 \\
Bamposht Fault & 92 & 8.01 & 0.12 & 0.13 & 0.1 & 0.2 & 0.14 & 0.13 \\
DamenFault & 93 & 7.04 & 0.06 & 0.06 & 0.07 & 0.07 & 0.08 & 0.06 \\
Simish Fault & 6 & 7.43 & 0.56 & 0.54 & 0.53 & 0.95 & 1.3 & 0.77 \\
Soran Fault & 46 & 7.38 & 0.15 & 0.17 & 0.14 & 0.28 & 0.2 & 0.18 \\
Sartang Fault & 48 & 7.38 & 0.15 & 0.16 & 0.12 & 0.25 & 0.16 & 0.16 \\
Kand Fault & 69 & 7.32 & 0.11 & 0.12 & 0.11 & 0.13 & 0.1 & 0.11 \\
\hline
\end{tabular}

According to these calculations, Maximum Calculation of Peak Ground Acceleration that imposed on Saravan is 0.92 of Gravitational Acceleration and it is a result from Saravan Fault Actions.

\section{Conclusion}

According to Satellite Images, Saravan Fault is a dextral reverse fault. There aren't many instrumental earthquakes in this area and surficial focus is located on central district then it has more earthquakes than other areas. This fault passes through $12 \mathrm{~km}$ from Saravan that it is the most dangerous fault for this city. It can shake this area $(270 \mathrm{~km})$ with magnitude of 8.29 that its acceleration will be equal to 0.92 of gravitational acceleration. By combination of the whole morphotectonic and earthquakes data, it can be determined the tectonic activities of this region. The studying of regional morphotectonic units indicate that the whole region is active tectonically and regarding to the studies, Saravan fault has more activities in the middle part than its two northwestern and southeastern extremes. The mean calculated values of geotectonic indices of mountain front sinuosity, the ratio of the valley bottom on its height and the $\mathrm{V}$ ratio are 76.1, 0.98 and 77, respectively. These values indicate high tectonic activity in Saravan region.

\section{References}

[1] Aqanbaty, A. (2004) Geological y of Iran. Geological Survey of Iran, Tehran.

[2] Sadat, M.A. (1993) Tectonic Map of Iran. Published by the Geological Survey.

[3] Stockline, J., Eftekhar-Nezad, J. and Hushmandzadeh, A. (1973) Reconnaissance Geology in Central Lut. Geological Survey of Iran (in Persian), Report No. 22, 86.

[4] Bull, W.B. and Mcfadden, L.D. (1977) Tectonic Geomorphology North and South of the Garlok Fault. California. 8th Annual Geomorphology Sym., New York.

[5] Jami, M., Javadi Mousavi, E., Hadizadeh, A. and Pourkermani, M. (2013) The Evaluation of Saravan Fault Activities in Iran on the Basis of Geomorphologic Evidences. Indian Journal of Science and Technology, 6.

[6] Solgi, A. (2009) Morphotectonic. Copyright MIT, Islamic Azad University, Tehran.

[7] Pour-Mohammadi, B. (1996) Morphotectonic Karkheh River. Proceedings of the 4th Seminar on River Engineering. Chamran University, 17.

[8] Ambraseys, N.N. and Melville, C.P. (1982) A History of Persian Earthquakes. Cambridge University Press, Cambridge, 2. 